\title{
INNOVATIVE STRATEGIES FOR EDUCATION OF ROMA CHILDREN IN PRIMARY SCHOOL
}

\author{
Rumyana Neminska ${ }^{1}$, Tanya Borisova ${ }^{2}$
}

\begin{abstract}
The problem with the education, socialization and upbringing of Roma children in Bulgaria is serious and requires the joint efforts of universities and schools. For many of these children, education is not a value. They study only in primary school and then remain traditionally in their family. It must be recognized that traditional family values and traditions for the Roma have the force of law. Many Roma families managed to socialize by leaving the ghetto and settling in Bulgarian communities - but many of them do not want to change their lifestyle. The cooperation between the schools and the university is presented in the university project "Innovations in the socialization of bilingual students through communication and speech development" presented here. A methodological innovation for the education of Roma children has been introduced. This innovation combines tradition (Roma fairy tale) and the development of reader literacy, thinking, and solving cases. A total of 415 Roma students participated in the empirical study. With their participation in the project it is established that they increase their reading skills, learn the Bulgarian language better and develop critical thinking.
\end{abstract}

UDC Classification: 37.01, DOI: https://doi.org/10.12955/pss.v2.233

Keywords: school, education, Roma, methodology

\section{Education as a value for the Roma}

The context of Roma education has an important role to play in promoting inclusion, even in segregated or semi-segregated systems. The contribution of Roma communities to the societies in which they live is often overlooked. This promotes the notion that these communities are marginal and insignificant, thus strengthening their status as outsiders. Bowers, a Roma journalist, describes the impact of this fact as follows: "Go to most museums, libraries and schools and nothing about our history and culture is stored or taught. The result is widespread ignorance about who we are, which sometimes turns into hatred, fear and misunderstanding. In schools, children learn more about the Romans, the Vikings or even the fairies than they do about our cultures and what we have contributed to this world". Similarly, Ofsted speaks of an "invisible minority ethnic group" (Ofsted, 2003).

Some members of the Roma community are proud and open with their identity, but others choose, where possible, to "pass" as a member of the community in which they study and live. Children with mixed cultural values, both within Roma communities and in other immigrant communities, are insecure about their core values and cultural heritage. When communities are socially excluded and accustomed to living in isolation and prejudice, they are likely to do everything possible to disguise their ethnicity.In combating these problems, school practices and the overall school ethos can play an important role in making members of minority communities feel recognized and respected and in realizing their education as a value for themselves, the community and civil society.

A number of scientific publications at home and abroad report on the deep variety of problems and attitudes related to the Roma community. Kiddle (1999) examines parents' attitudes toward educating their own children. Some parents expect their children to take on gender-specific roles in family relationships, which undermines their commitment to education and the core curriculum (Kiddle, 1999). At the same time, Roma children can be convinced that time spent at school can be better used in the study of intra-community trade.

Researchers Derrington and Kendall (2004) found that some parents support their children for professional careers, despite the traditional choices in which they have been raised for generations. Value-based education provides a better quality of education for all children and helps to change discriminatory attitudes. Schools provide a context for children's first connections to the world outside their families, enabling the development of social relationships and interactions. Respect and understanding increase when students with different abilities and from different backgrounds play, communicate and learn together. When education is value-oriented, then it is built on the concepts of civic participation, employment and public life.

The work within such education is carried out by teachers who have the potential to be tolerant, inclusive, responsible and active citizens. They work with programs that include local themes for the

\footnotetext{
${ }^{1}$ Trakia University, Faculty of Education, Stara Zagora, Bulgaria, neminska@abv.bg

2 Trakia University, Faculty of Education, Stara Zagora, Bulgaria, borisova.t@abv.bg
} 
contribution of marginalized and minority groups. They avoid binary stories of good and bad and adapt the curriculum to the learning style of different children.

\section{Methodological innovations in the training of teachers of Roma students}

The activities based on the project "Innovations in the socialization of bilingual students through communication and speech development" are based on methodological innovations related to the education of Roma students. They are based on project-based, problem-based and motivating learning aimed at reading with an understanding of Roma stories and developing reading literacy. The activities based on the project "Innovations in the socialization of bilingual students through communication and speech development" are based on methodological innovations related to the education of Roma students. They are built upon project-based, problem-based and motivating learning aimed at reading with an understanding of Roma stories and developing reading literacy.

The first construct of the methodological innovation is the acquaintance with Roma tales. The introduction of Roma fairy tales for Roma students to study turns out to be crucial for their selfknowledge, increasing their self-confidence and motivation to learn. On the other hand, students of non-Roma origin meet fairy-tale characters unknown to them, which enriches their ideas about the world and man. "Roma Tales" are designed as beautiful books, with appropriate illustrations and this enhances their aesthetic impact. They are taught by teachers through interactive methods and this makes them even more influential. Fairy-tale Roma heroes, as well as the heroes of other ethnic groups and peoples, are bearers of ancient human values. At the same time, they carry the specifics of the Roma soul, arouse readers' curiosity and provoke an evaluative attitude.

The second construct is the application of interactive methods in getting to know and thinking about the Roma fairy tale. Interactive methods are used such as:

Discussion is a major step in considering the plot and characters of fairy tales.

This the stage in which the points of view are clarified, hypotheses are formed, and decisions are made.

Brainstorming. This is a discussion technique. In this method, Roma students solve a problem from a fairy tale,

Roleplay. This method is applied within the role play. Students take on the role of a fairytale character and develop creativity.

The third component of the methodological innovation is solving cases related to the fairy tale plot. The application of knowledge is carried out by solving cases, answers to problematic questions and applied creative tasks related to the plot of the story. As Borisova writes, "the traditional methodology of reading instruction leaves a large number of Roma students illiterate" (Borisova, 2018). In their pedagogical school practice, teachers direct children to decode the text. They strive to teach children to read without spelling. All this leaves in the background the check whether the child understands what he is reading and whether he can extract information from the text. Roma children, for whom Bulgarian is not their mother tongue, naturally face this problem. They read slowly and with difficulty. Their attention is absorbed by the decoding of the text. Thus, reading comprehension lags behind and results in being a prerequisite for their demotivation towards learning and independent work. Complex texts found in reading textbooks for third and fourth grade is one of the main reasons for the Roma children lagging behind in learning. The premature dropping out of the Roma process by the Roma children lies in the selection of the educational content. This gives their lower motivation a deeper understanding of the texts they read.

The change in the methodologies of teaching Roma students is the way to include more Roma children in education. This methodological change affects in the first place the acquisition of the Bulgarian language, enrichment of the lexical stock, activation of the vocabulary through written and spoken communication. Borisova directs methodological innovations to the idea of reviewing and rethinking teaching methods, "ways to make the modern child read, think, understand and appreciate what is read." (Borisova, 2018). In this sense, Delcheva outlines the role of the teacher, teaching Roma students. She comment on the concept of professional competence as "a set of knowledge, skills, attitudes and behavior to achieve results (levels of performance) in a given professional role" (Delcheva, 2020). In this sense, case study teaching is one of the ways in which learning strategies can be actively implemented. Through the application of the case study the educational-cognitive and 
social-axiological experience of the students is taken into account, and real learning situations are constructed. Thinking about the problems in the case study develops skills for analytical-critical interpretation of the created problem situation. The case studies are strongly related to increasing the motivation and interest of Roma students. The use of case studies contributes to the understanding of the learning material, which is more important than memorizing the correct answers. In the theory of case study teaching, there are two directions, considering the case as a tool of teaching and learning:

- Cases with an emphasis on the search for only one possible solution related to the fairy tale plot. The teacher sets possible solutions, directions of work, provokes the search for arguments for and against the choice made or the proposed stages of work.

- Cases with an emphasis on finding more than one solution related to the fairy tale. In this process of training, preconditions are created, provoking the asking of questions and the search for answers.

Topics that are applied in the case study of Roma students are related to stories about gender, knowledge, language, way of life, folklore, culture, family - the life values of Roma families. The results achieved in the application of the methodological innovation are presented in the next paragraph.

\section{Empirical results and analysis}

How do young Roma students react when learning these stories? From the observations of lessons, as well as in the informal communication with the children and their teachers in the cities of Rakitovo, Pazardzhik, Dve Mogili, Stara Zagora, Nova Zagora and others, the conclusion is that Roma students enjoy reading tales from their folklore. They are motivated, purposeful and especially proud that the characters in fairy tales have their qualities and character. A study on reading literacy and reading comprehension by third and fourth - grade students on Roma fairy tales involved 19 classes, with a total of 415 students, of which 97 were ethnic Bulgarians, 300 Roma and 8 from other ethnic groups (Turks, Jews, Armenians). All the qualities of reading are detected - speed, mechanism, correctness and expressiveness, as well as reading with understanding and extraction of information in the direction - determining the theme of the text, determining the main characters and their qualities, as well as the lesson of the story. According to the PISA criteria, this is the first level of extracting information from text.

Like any ethnic group, the Roma are ready to study their own traditions and culture. Roma students get excited when they find in the fairy tales they study the same thoughts, feelings and characteristics that they have. That is why they are motivated to read fairy tales with Roma themes. The other students - Bulgarians and others, accept the Roma tales as well as the tales of other peoples, placed in the textbooks. There was not a single protest, not a single resentment that a tale from Roma folklore would be considered. Developing tolerance - that which is built in the child, in the student, in the teacher as a mediator in the educational process, in the citizen, is an attitude, a skill for change through interaction with otherness. It is primarily concerned with acknowledging the existence of differences, their importance as they are not exaggerated or ignored, but regulated - combined so that they are tolerable for all.

What are the results of the pedagogical research?

There are no significant differences in the speed of reading of Bulgarian and Roma fairy tale. In both cases, there is a decline in the reading rate of children who have difficulty reading, and at the same time, it increases within the educational minimum. It is assumed that in the initial reading, it is not possible to fully achieve the development of reading speed, which is possible to achieve only in terms of the mechanism and correctness of reading. Speed is achieved indirectly, not directly, in the process of complete mastery of reading as a technique and understanding - improving reading habits and optimizing comprehension.

With the reading mechanism - the syllables of children increase, but on the other hand, all those who read whole words and sentences increase their achievements. The tendency to read sentences is especially impressive. $48 \%$ of the surveyed persons (against $44 \%$ ) read fluently in a Roma story. Probably this is due to the desire to quickly grasp the meaning of what is read.

The proper reading of the text means reading without repetitions, without adding or omitting sounds, syllables and words, without violating the coordination between words and their grammatical forms, 
and in compliance with the requirements for correct Bulgarian pronunciation. The analysis of the results regarding the correctness of the reading shows that $22 \%$ of the students do not make mistakes in a Bulgarian fairy tale, and $26 \%$ of the children do not make mistakes in a Roma fairy tale. The reason lies only in the accessibility and understandable everyday language of Roma fairy tales. The most common and difficult to overcome mistakes are the utterance of the sound side of the word and violation of the norms of orthography in the Bulgarian literary language. These errors arise from the influence of the mother tongue and from the mobility of the accent in the Bulgarian language.

Reading comprehension is related to the perception and interpretation of the artistic text. It was decided that it is better for the respondents to use the term understanding the information from the text situation, because it corresponds to some features of the process of perception of an artistic text by Roma students. In them, understanding is related both to the direct interpretation of the word, its lexical meaning, and to its sound in a related text. In this situation, it is very difficult to talk about the whole process of perception, given that the artistic style is rich in tropes, and children of the Roma ethnic group first get acquainted with the direct meaning of words and have much more difficulty when trying to perceive their figurative meaning. That is why a fairy tale was chosen, which as a genre is easy for children to perceive, and its understanding does not hinder 9 to -11- year - old students. According to the educational minimum, they must be able to discover the theme, the main characters, the climax and the lesson of the fairy tale.

From the surveyed 415 students, interesting and parallel data were obtained in the understanding of Bulgarian and Roma fairy tales. While the first three criteria make some distinction in student achievement, and in understanding, the results overlap and will be commented on simultaneously. Even in some respects, the understanding of reading a Roma fairy tale precedes the understanding of reading a Bulgarian fairy tale. The only logical explanation lies in the fact that in the Roma fairy tale, Roma students discover their own soul, rely on their own way of life, manners and customs. It is clear that they need to know the folklore of their own ethnic group, to study it and to talk to others about it. Over $92 \%$ of the students have unmistakably defined the theme of the text in both tales; $88 \%$ have correctly identified the main characters in the Bulgarian fairy tale, and $100 \%$ - in the Roma; $84 \%$ found the climax correctly. It is even better that $93 \%$ identified the lesson in the Bulgarian folk tale, and $96 \%$ have correctly defined the lesson in the Roma folk tale. Once again, it was shown that students could identify the lesson of fairy tales on their own in an interactive way without the mediation of the teacher. The opinion was confirmed that when the story is in line with the moral needs of young students, when it contains vocabulary familiar to them and awakens their desire for self-knowledge, they enjoy reading and thinking about human values, no matter which culture created them.

\section{Conclusion}

The constructed methodological framework for training Roma students under the project "Innovations in the socialization of bilingual students through communication and speech development" proved to be very effective and efficient. By applying the described methods, the students increased their motivation for learning, reading comprehension and reading literacy. The lessons were saturated with their participation and expectation for active involvement in learning situations. In practice, a strategy for effective learning of Roma students is implemented in the classroom through methodological innovation.

\section{References}

Borisova, T. (2018) Savremennoto obuchenie po ogramotyavane I chetene s razbirane 1.- 4. class. [Modern literacy and comprehension training 1-4. class], Kota, Stara Zagora.

Borisova, T. (2018) Romskite prikazki - vazmojnost za interkulturna komunikazia. [Roma tales - an opportunity for intercultural communication] Professional Forum magazine http://www.dipku-sz.net. br. 3

Delcheva, T., (2020) Formirane na profesionalni konpetentnosti za sozialna rabota u studentite po sozialna pedagogika. [Formation of professional competencies for social work in students of social pedagogy], ed. Kota, Stara Zagora

Derrington, C. and Kendall, S. (2004). Gypsy Traveller Students in Secondary Schools: culture, identity and achievement. Stoke-on-Trent: Trentham Books.

Ofsted (2003), Office for Standards in Education, Children's Services and Skills Provision and Support for Traveller pupils London: Ofsted Publications Centre. Available at: http://www.ofsted.gov.uk/resources/provision-and-support-for-travellerpupils

Kiddle, C. (1999) Traveller Children: a voice for themselves. London: Jessica Kingsley. 